\title{
Establishment of Average Body Measurement and the Development of Block Patterns for Pre-School Children
}

\author{
Igbo, C. A. (Ph.D) \\ Department of Vocational Education' University of Nigeria, Nsukka, Enugu State Nigeria
}

\begin{abstract}
There is a need for mass production of garments for pre-school children to meet their clothing needs. Clothing has been included in some of the items banned from importation in order to save foreign exchange for provision of raw materials for the manufacturing sector in Nigeria. The purpose of this study was to establish average body measurements of pre-school children of ages 2 to 5 years, adapt block patterns for them and standardize the patterns drafted. Fifteen design criteria based on comfort were utilised to standardize the patterns drafted. The population of the study comprised all pre-primary school children in the 180 schools in Cross River State of Nigeria. The sample consisted of 400 pupils. Prototype garments were produced and modelled by four pre-school children of ages 2,3,4 and 5 years. The garments were evaluated by five judges. Results after analysis of data with mean and ANOVA provided average body measurements and also indicated that the patterns developed were appropriate for the target group. The results also showed that there is no significant difference in the mean body measurement for height and backneck to waist for ages 2,3,4 and 5 years. The average body measurements obtained are therefore recommended for drafting and adapting patterns for the target group and the standardized block patterns are also recommended for clothing manufacturing companies.
\end{abstract}

\section{Introduction}

A pre-school child is a child between the age of three to five years old (Federal Republic of Nigeria (1998). Pre-school children according to Bray (1999) grow all the time. As they grow there is a change in their shape as well as in their size. This growth according to Aldrich (1999) decreases as they approach puberty and is similar in both male and female children. At puberty children experience a growth spurt. Pre-school children have certain rights which include the right to clothing (United Nation Children Education Fund (UNICEF) 1989).

Clothing is anything worn for protection (Clayton 1994). Clothing also does more than just meeting individuals' need for comfort and protection but also gives a first impression. Clothing helps in self-expression and communicates messages to other people. It also reflects personality and life style. Through clothing basic human needs are satisfied which are both physical and socio-psychological (Johnson and Forster 1990). Some of these needs as earlier stated include protection from rain, hot sun and cold weather. Hurlock (1978) observed that clothes give children impression of growing up, help children to identify themselves as individuals and help camouflage their physical defect and disabilities among others. Sasse (1997) also stated that clothing helps children to be independent at an early age. This sense of independence and a sense of pride produced by clothes are important for a childs emotional development.

Children's wear is no longer a neglected area of design. Designers of children's clothes should be aware of the way that a child's body grows and should be able to recognise the shape of child at a particular state. Children's wear offers special opportunities to designers to experiment with colour decoration and design detail (Aldrich 1999).

Patterns for children are cut very much as patterns for adults using the same basic methods of style and pattern adaptation. Children's styles are even simpler and less varied. Pattern drafting according to Tuit (1983) is a method of obtaining patterns by working from the 
measurement of a figure according to a set of instructions and drawing a shape on paper or card. It is also a process of obtaining component parts of a garment silhouette in shapes of paper following lines that relate to the body contour (Utuk 1991). The shape of the pieces of paper when tested according to her are then laid on the fabric and cut out for clothing. Cooklin (1994) sees pattern drafting as a bridge function between design and production based on a sketch which can be turned to a garment. Igbo and Iloeje (2003) however stated that pattern drafting is an engineering approach to the production of pattern based on a set of body measurements and instructions. Patterns for clothing production can be obtained in the following ways, flat pattern method, knock off design, and the computer aided design (CAD) (Hollen and Kundel 1993). Patterns help in mass production of children's dresses.

The advent of Globalisation which means a world liberalized of barriers to trade and investment in which corporations can produce and sell almost any goods and services anywhere in the world has led to many mass produced children's clothing from the far East and developed world finding its way into Nigeria. Globalisation according to Ayodele (1995) has brought about increased movement of goods, services, capital, people and information across national borders. However during the announcement of the annual budget for the year 2004, President Obasanjo of Nigeria announced the ban on the importation of certain goods which include clothes and textiles thereby encouraging Nigerians to go into mass production of clothing items. Mass production of clothes is only possible with the use of patterns. Many of Nigerian's indigenous tailors, and seamstresses are trained to make made-to-measure dress items without the use of patterns. (Iloeje 1995). Nigerian tailors presently have an odious task in view of their heavy dependence on taking of individual body measurements of customers before constructing dress items for them. This task can however be reduced by the use of patterns which are either commercial or drafted. Commercial patterns are however included in the luxury goods whose importation is banned in Nigeria.

As a first step towards making pattern for pre-school children dresses available to the tailors, average measurements of the different parts of the body must be established. Children of the same height can have varied arm and leg measurements (Aldrich 1999). The environment where a child is brought up can bring about significant differences in height and size. Aldrich (1999) discovered that children of working class parents - the managerial and professional appear taller but not heavier than children of semi-skilled and unskilled parents. Igbo (2002) also stated that environmental factors like adequate nutrition which is in turn affected by availability of and accessibility to adequate food have a part to play in the height and weight of a child. Aldrich (1999) established the following average body measurements for some body parts for children aged 2,3,4 and 5 respectively: height $92,98,104$ and $110 \mathrm{~cm}$, chest $53,55,57,59 \mathrm{~cm}$, waist $51,53,54,56 \mathrm{~cm}$, sleeve length $32,34.5,37,39.5 \mathrm{~cm}$. Bray (1999) also stated that some of the special problems in producing children's clothing's is the problem of change in size and shape of a growing child. To deal with problem of changing size and shape, the present study will establish average sizes and proportion which would be used to develop block pattern for adaptation into various styles which will in turn help in mass production of garments for the target group.

However to obtain accurate patterns, accurate measurements must be carried out. Clayfon (1994) stated that measurements should be taken snugly but not tightly over the undergarments. Tapes must be held parallel to the floor during measurement. Without accurate measurements, accurate patterns for mass producing clothing items for pre-school children cannot be obtained. The objectives of the study therefore were

1. To establish average body measurements of pre-school children of ages 2 to 5 years.

2. Determine which body measurements showed marked variation from the group mean.

3. Draft the basic blocks for the different age groups (2, 3, 4 and 5 year olds) - front bodice blocks, back bodice blocks and sleeve blocks. 
4. Evaluate the blocks developed for the pre-school children for fit in order to standardize them.

The study also tested one null hypothesis - There is no significant difference in the mean body measurement for height and nape to waist measurement of pre-school children of ages 2, 3, 4 and 5 years.

\section{Methodology}

\section{Design of the study}

The procedure utilised for carrying out the study was as follows:

1. Taking the body measurement of pre-school children of ages 2, 3, 4 and 5 years old.

2. Obtaining the mean or average measurements of the different body parts measured.

3. Drafting the block patterns.

4. Cutting out and stitching of the garment parts.

5. Modelling of the garment by the pupils.

6. Evaluation of the garment based on an evaluation criteria chart.

7. Obtaining the standardized block patterns.

\section{Area of the Study}

The study was carried out in the Cross Rivers State of Nigeria. Cross River is one of the states in the South South geopolitical zones of Nigeria. The state is divided into six educational zones namely Calabar, Akamkpa Ugep, Ikom, Ogoja and Obudu. The study took place in three zonal areas - Ikom, Ogoja and Obudu.

\section{Population of the Study}

The six educational zones have 180 pre-primary schools with a population of 20,500 preprimary schools. Information to this effect was obtained from the state ministry of education office of statistics. Nine thousand two hundred pupils who formed the population of the study were from the three zones that were studied.

\section{Sample for the Study}

A multi-stage sampling technique was utilised. Three zones were sampled out of the six zones using stratified random sampling technique. These zones have 88 pre-primary schools. Fifteen schools were randomly sampled from the eighty-eight schools. For the pre-school pupils proportionate sampling was used in selecting 250 children from Ikom zone, 100 from Ogoja and 50 from Obudu to give a total of 400 pupils.

\section{Instrument for Data Collection}

A body measurement chart on essential body measurements needed for drafting flat patterns for the study was developed. The instrument comprised two sections. Section A contained background information on age, name of school, local government area and parents profession. Section B contained the body parts that were measured and the measurements obtained. A total of ten (10) body parts were measured namely height, chest, waist, across back, back neck to waist, sleeve length, under sleeve length, arm circumference, wrist and half length. 

Igbo, C. A. (Ph.D)

\section{Data Collection Technique}

This was carried out in 3 stages with the help of two research assistants.

1. Background information on the students as seen in section A was recorded.

2. Body measurements were taken over the school uniforms. Cardigans and vests were removed to avoid bulk. Fibre - steel tape was utilised for the measurements of the total 400 pupils and recorded.

3. Means of the measurements of the body parts were obtained and used to draft the front bodice, back bodice and sleeve blocks for the different age groups $(2,3,4$ and 5 year olds) using the flat pattern drafting method.

4. The pattern pieces were cut out on soft plain cotton fabric and stitched to obtain four garments for 2, 3, 4 and 5 year olds respectively.

5. The garments were trued on four pre-school children of ages 2, 3, 4 and 5 years and then evaluated. The evaluation was carried out by five judges based on an evaluation criteria chart. The criteria for evaluation which was based on comfort included the following front neck width, front neck depth, shoulder seam length, shoulder slope, front chest width, chest line ease, waist line ease, armsyce depth, ease at arm circumference and sleeve cap fullness. The evaluation criteria chart had five point scale items ranging from much too small, slightly too small, satisfactory slightly too large and much too large. The scale was assigned these following scores $1,2,3,4$ and 5 respectively.

\section{Data Analysis Technique}

The mean was used to analyse the data obtained from the measurement of the following body parts for all the ages - waist, across chest, height, across back back neck to waist (nape to waist), sleeve length, under sleeve length, wrist, arm circumference and half length.

1. A one way analysis of variance ANOVA was utilized to test the null hypothesis at 0.05 level of significance.

2. Mean of the body parts obtained was used to draft the blocks using the flat pattern method.

3. the five point rating scale in the evaluation criteria chart was analysed using mean. Any criteria with a mean of 3.00 was accepted while any below or above was rejected and the pattern piece with the rejected criteria was revisited for correction.

\section{Findings}

1. Mean measurements of the ten different body parts were obtained (see Tables 1 5).

2. Variabilities were observed in the measurement of the different body parts for the different ages (2, 3, 4 and 5 years olds) see Table 5 .

3. There was no significance different in the mean body measurements for height and nape to waist measurement of the pre-school children of ages 2, 3, 4 and 5 (see Table 6).

4. The following block patterns were obtained:

i. basic bodice front block

ii. basic bodice back block

iii. basic sleeve block 
5. Based on the scores from the rating scale in the evaluation criteria chart, after the garment has been "modelled" minor adjustments were made on the blocks to produce standardized basic bodice front, basic bodice back and sleeve block. (see table 7).

Table 1 Mean Body Measurements $(\mathrm{cm})$ of 2 year old Pre-school Children

\begin{tabular}{lcccc}
\hline Body measurement & Min & Max & Mean & SE \\
\hline Waist & 51.7 & 56 & 54.0 & 0.19 \\
Across chest & 50.4 & 55 & 52.9 & 0.15 \\
Height & 82.5 & 88 & 85.80 & 0.13 \\
Across back & 20.5 & 24.5 & 22.56 & 0.12 \\
Back neck to waist (Nape to waist) & 23.5 & 27.9 & 26.0 & 0.14 \\
Sleeve length & 21.5 & 27.8 & 24.9 & 0.21 \\
Under sleeve length & 19.5 & 23.9 & 22.56 & 0.30 \\
Wrist & 14.00 & 17.1 & 15.55 & 0.01 \\
Arm circumference & 16.5 & 21.8 & 19.1 & 0.18 \\
Half length & 22.1 & 25.4 & 24.0 & 0.12 \\
\hline
\end{tabular}

$\mathrm{N}=100 ;$ Min $=$ minimum measurements; Max $=$ maximum measurements; and $\mathrm{SE}=$ Standard Error

Table 2 Mean Body Measurements $(\mathrm{cm})$ of 3 year old Pre-school Children $(\mathrm{N}=100)$

\begin{tabular}{lcccc} 
Body measurement & Min & Max & Mean & SE \\
\hline Waist & 58.7 & 65 & 61.8 & 0.17 \\
Across chest & 55 & 59.4 & 57.2 & 0.12 \\
Height & 99.5 & 104.8 & 102.5 & 0.19 \\
Across back & 21.5 & 25.6 & 23.8 & 0.127 \\
Back neck to waist (Nape to waist) & 24.5 & 29.1 & 20.97 & 0.14 \\
Sleeve length & 28.5 & 32.7 & 30.70 & 0.13 \\
Under sleeve length & 23.5 & 28.3 & 26 & 0.1498 \\
Wrist & 14.5 & 17.8 & 16.1 & 0.8098 \\
Arm circumference & 19.5 & 24 & 21.92 & 0.143 \\
Half length & 21.5 & 25.9 & 24.045 & 0.145 \\
\hline
\end{tabular}

Min $=$ Minimum measurement; $\operatorname{Max}=$ Maximum measurement; and SE $=$ Standard Error

Table 3 Mean Body Measurements of 4 year olds $(\mathrm{cm}) \mathrm{N}=100$

\begin{tabular}{|l|c|c|c|c|}
\hline Body measurement & Min & Max & Mean & SE \\
\hline Waist & 56.8 & 68.4 & 61.98 & 0.32 \\
Across chest & 57.1 & 61.4 & 59.5 & 0.13 \\
Height & 94 & 106.8 & 101 & 0.42 \\
Across back & 22.5 & 27.2 & 24.86 & 0.15 \\
Back neck to waist (Nape to waist) & 25.5 & 29.9 & 28.0 & 0.14 \\
Sleeve length & 29.5 & 33.8 & 31.5 & 0.13 \\
Under sleeve length & 27.5 & 33.6 & 30.36 & 0.186 \\
Wrist & 15 & 18.6 & 16.14 & 0.11 \\
Arm circumference & 20.4 & 24.9 & 22.67 & 0.1435 \\
Half length & 27.5 & 33.5 & 30.5 & 0.34 \\
\hline
\end{tabular}

Min = minimum measurements; Max = maximum measurements; and SE $=$ Standard Error 
Establishment of Average Body Measurement and the Development of Block Patterns for Pre-School Children Igbo, C. A. (Ph.D)

Table 4 : Mean Body Measurements of 5 year old $(\mathrm{cm}) \mathrm{N}=100$

\begin{tabular}{lcccc}
\hline Body measurement & Min & Max & Mean & SE \\
\hline Waist & 58 & 67.2 & 62.96 & 0.27 \\
Across chest & 55 & 65.4 & 62.3 & 0.19 \\
Height & 104 & 109.5 & 107.2 & 0.15 \\
Across back & 22.5 & 27.2 & 24.86 & 0.15 \\
Back neck to waist (Nape to waist) & 27.5 & 32 & 29.9 & 0.1447 \\
Sleeve length & 35.5 & 39.4 & 37.5 & 0.133 \\
Under sleeve length & 30.5 & 41.8 & 35.26 & 0.428 \\
Wrist & 15.5 & 19.6 & 17.2 & 0.118 \\
Arm circumference & 21.5 & 25.7 & 23.45 & 0.132 \\
Half length & 28.5 & 33.9 & 30.63 & 0.145 \\
\hline
\end{tabular}

Min $=$ minimum measurements; Max $=$ maximum measurements; and $\mathrm{SE}=$ Standard Error

Table 5 Mean Body Measurements (cm) for ages 2 - 5 and standard Error of the means

\begin{tabular}{lcccc}
\hline Body measurement & 2 year olds & 3 year olds & 4 year olds & 5 ys. olds \\
\hline Waist & $54.0 \pm 0.19$ & $61.70 \pm 0.176$ & $61.98 \pm 0.32$ & $62.96 \pm 0.27$ \\
Across chest & $52.90 \pm 0.15$ & $57.20 \pm 0.12$ & $59.50 \pm 0.13$ & $62.30 \pm 0.19$ \\
Height & $85.80 \pm 0.13$ & $101.0 \pm 0.40$ & $102.50 \pm 0.19$ & $107.20 \pm 0.15$ \\
Across back & $22.56 \pm 0.14$ & $23.50 \pm 0.13$ & $24.89 \pm 0.15$ & $25.9 \pm 0.15$ \\
Back neck to waist (Nape to waist) & $26.0 \pm 0.14$ & $26.97 \pm 0.14$ & $28.0 \pm 0.14$ & $29.90 \pm 0.14$ \\
Sleeve length & $24.9 \pm 0.21$ & $30.70 \pm 0.13$ & $31.50 \pm 0.13$ & $37.50 \pm 0.13$ \\
Under sleeve length & $22.56 \pm 30$ & $26.0 \pm 0.15$ & $30.36 \pm 0.19$ & $35.52 \pm 0.44$ \\
Wrist & $15.55 \pm 0.01$ & $16.10 \pm 0.01$ & $16.14 \pm 0.11$ & $17.2 \pm 0.12$ \\
Arm circumference & $19.10 \pm 0.18$ & $21.92 \pm 0.14$ & $22.67 \pm 0.14$ & $23.45 \pm 0.13$ \\
Half length & $24.0 \pm 0.12$ & $24.04 \pm 0.15$ & $30.5 \pm 0.18$ & $30.63 \pm 0.15$ \\
\hline
\end{tabular}

$\mathrm{N}=400 ;$ Min = minimum measurements; $\mathrm{Max}=$ maximum measurements; and $\mathrm{SE}=$ Standard Error

Table 5 shows that there are variabilities in the following:

i Height $(\mathrm{SE}=0.13-0.3)$, which showed the widest distribution of values for the four age groups

ii Under sleeve length (SE $0.15-0.44$ )

iii. Sleeve length (SE $0.13-0.3$ )

iv. Waist SE $(0.17-0.32)$

v. Across chest (SE $0.12-0.19)$

vi. Half length (SE $0.12-0.18)$

vii. Arm circumference (SE $0.13-0.18$ )

viii. Across back $\mathrm{SE}=(0.12-0.15)$

ix. Wrist $(\mathrm{SE}=0.1-0.12)$ which has the least variability for the four age groups. 
Table 6 One-way Analysis of Variance Summary Table examining the difference in the mean body measurement for Height and back neck to waist of preschool children of Ages 2, 3, 4 and 5 years.

\begin{tabular}{lllll}
\hline Variation & Sum of squares & Df & Mean Squares & F. Ratio \\
\hline Between means & $\mathrm{SSA}=73.08$ & $\mathrm{n}-1=3$ & $\mathrm{MSA}=57.69$ & $\frac{M S A}{M S E}=0.0224$ \\
With samples & $\mathrm{SSE}=0286.26$ & $(\mathrm{r}-1) \mathrm{n}=4$ & $\mathrm{MSE}=2571.56$ & \\
Total & $\mathrm{SST}=\mathrm{SSA}+\mathrm{SSE}=10459.3$ & $\frac{m-1}{7}$ & & \\
\hline
\end{tabular}

$S S A=173.08 ;$ SSE $=10286.26 ;$ SST $=S S A+$ SSE $=10459.3 ; \mathrm{MSA}=57.69 ; \mathrm{MSE}=252.56$

The above table shows that the calculated F-ratio is 0.0224 since the calculated f-ratio of 0.0224 is less than the tab f-ratio. Hence the null hypothesis was up held. The average body measurements in Table 5 were then used to draft the basic bodice front basic bodice back, and the sleeve block using the flat pattern drafting method. These blocks were then modelled on four children in the different age groups to obtain standardized block patterns, see figs. $1-4$ and $5-8$. Standardized block patterns - front bodice, back bodice and sleeve were obtained after, judgement by judges and corrected by the researcher (see figs 1-4).

Table 7

Mean Responses of Evaluation Criteria by Judges for all ages (2, 3, 4 and 5 years).

\begin{tabular}{llcccc}
\hline S./N & Criteria & \multicolumn{4}{c}{ Mean Response } \\
& & 2 years olds & 3 years olds & 4 years olds & 5 years olds \\
\hline 1. & Front Neck width & 3 & 2 & 3 & 3 \\
2. & Front Neck depth & 2 & 3 & 2 & 3 \\
3. & Shoulder seam length & 3 & 2 & 2 & 3 \\
4. & Shoulder slope & 2 & 3 & 3 & 3 \\
5. & Front chest width & 3 & 3 & 3 & 3 \\
6. & Waist line ease & 3 & 4 & 3 & 3 \\
7. & Ease across shoulder blades in back & 3 & 4 & 3 & 2 \\
8. & Waistline ease in front & 4 & 3 & 4 & 3 \\
9. & Waist line ease in back & 3 & 3 & 4 & \\
10. & Waistline placement in front & 4 & 3 & 2 & 3 \\
11. & Waistline placement in back & 3 & 4 & 3 & 3 \\
12. & Armscye depth & 3 & 4 & 3 & 3 \\
13. & Ease at arm circumference (biceps) & 4 & 3 & 3 & 3 \\
14. & Sleeve cap fullness & 3 & 2 & 2 & 3 \\
15. & Overall scare of garment & 3 & 3 & 3 & 3 \\
\hline
\end{tabular}



Igbo, C. A. (Ph.D)

\section{Remarks}

$2=$ slightly narrow, short, little

$3=$ Satisfactory, comfortable

$4=$ Slight too much ease and low
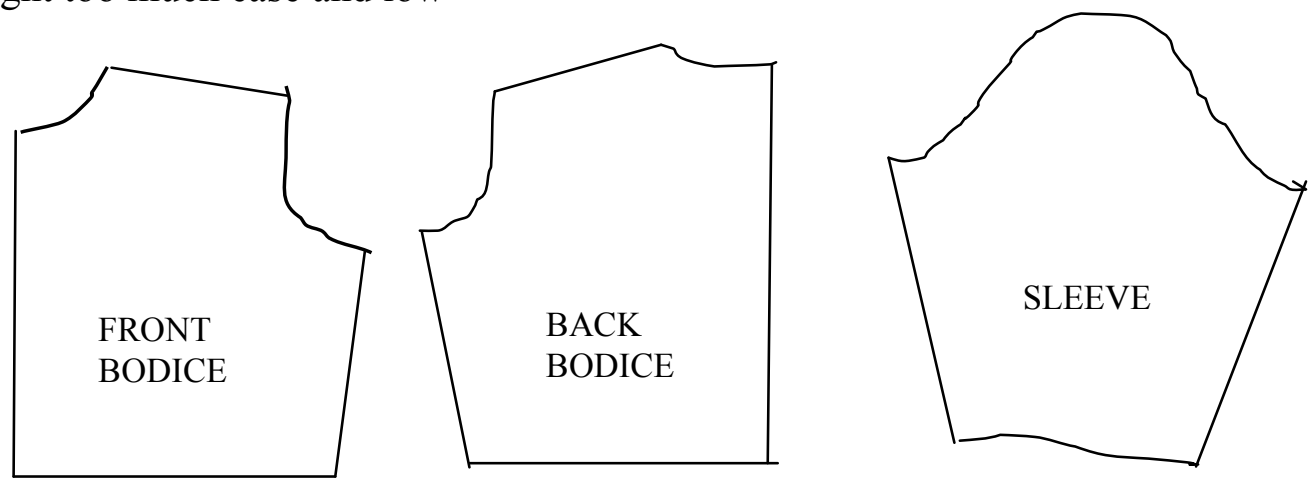

Fig. $1 \frac{1}{4}$ Block pattern for 2 year
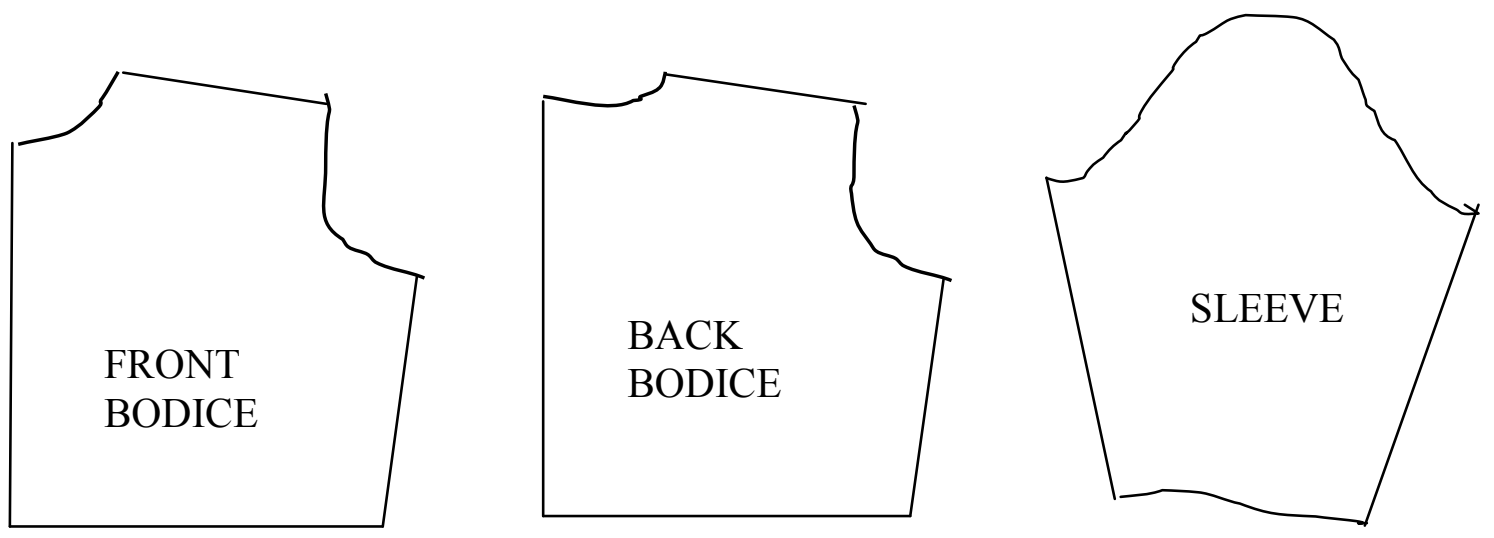

(Fig. 2

$1 / 4$ block patterns for 3 year olds).

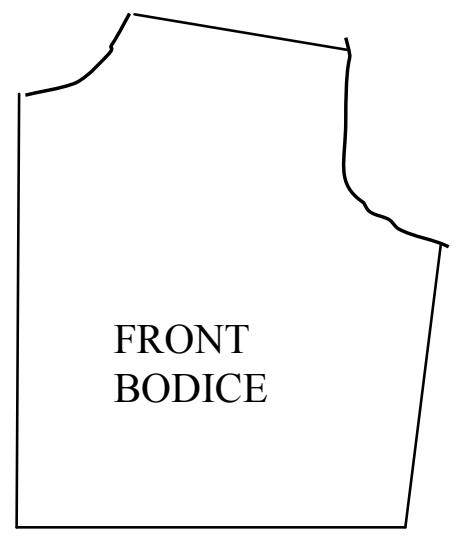

(Fig. 3
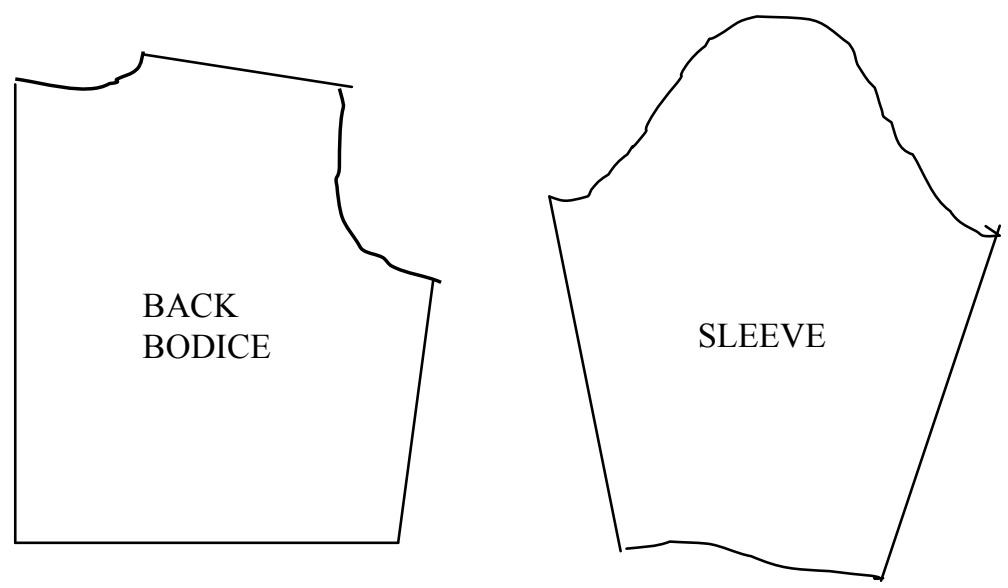

$1 / 4$ block patterns for 4 year olds). 
African Journal of Educational Studies in Mathematics and Sciences Vol. 3, 2005
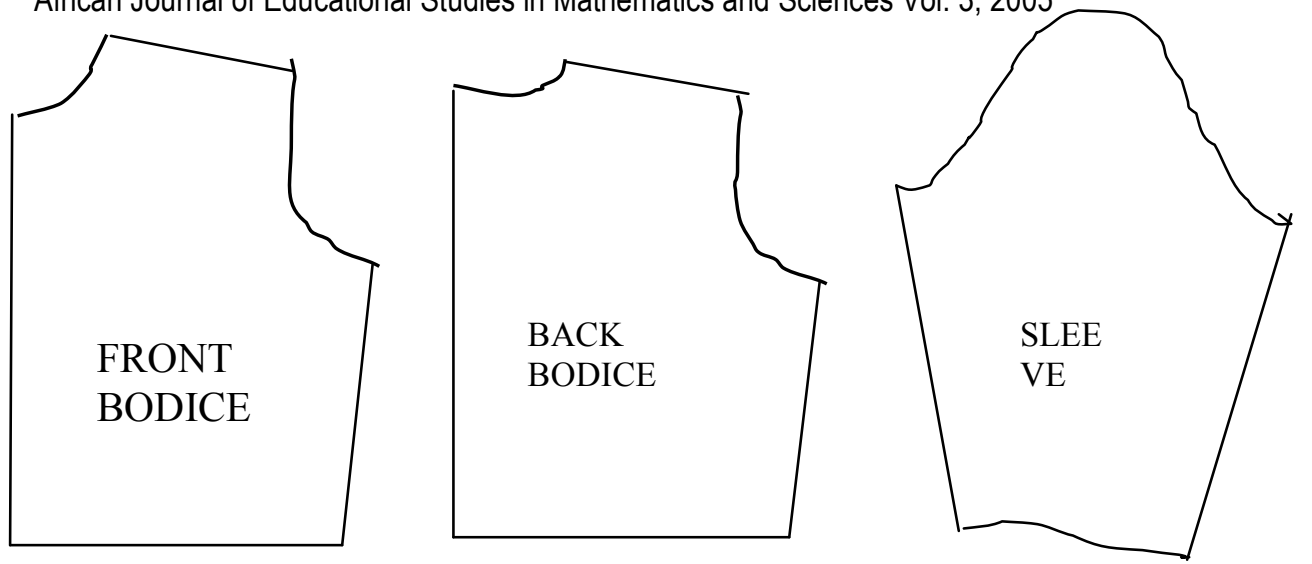

(Fig. 4: ${ }^{1 / 4}$ block patterns for 5 year olds).

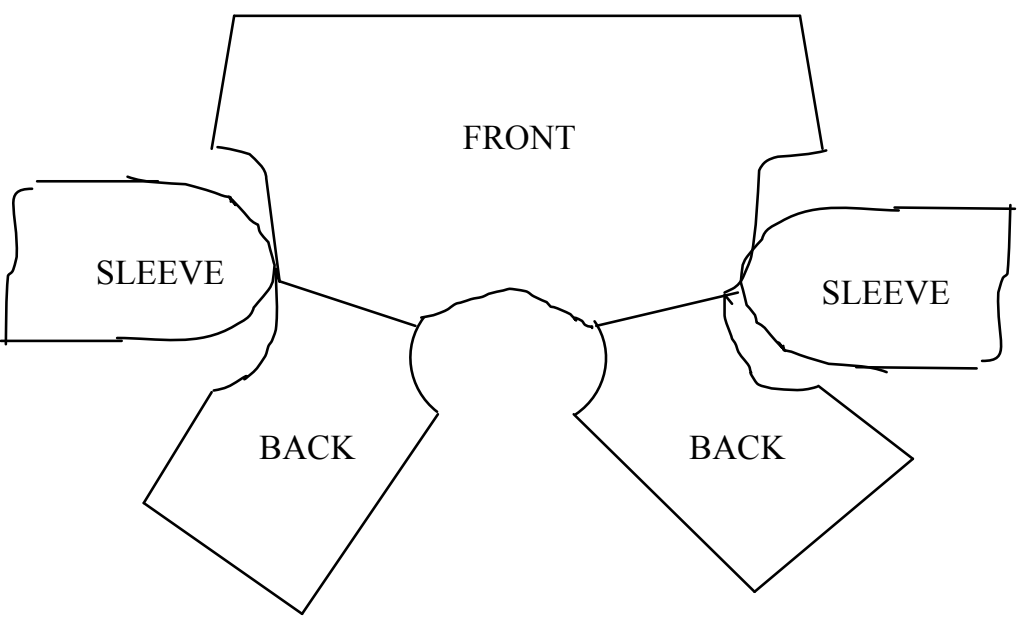

Fig. 5: ( 2 year olds) $1 / 4$ pattern

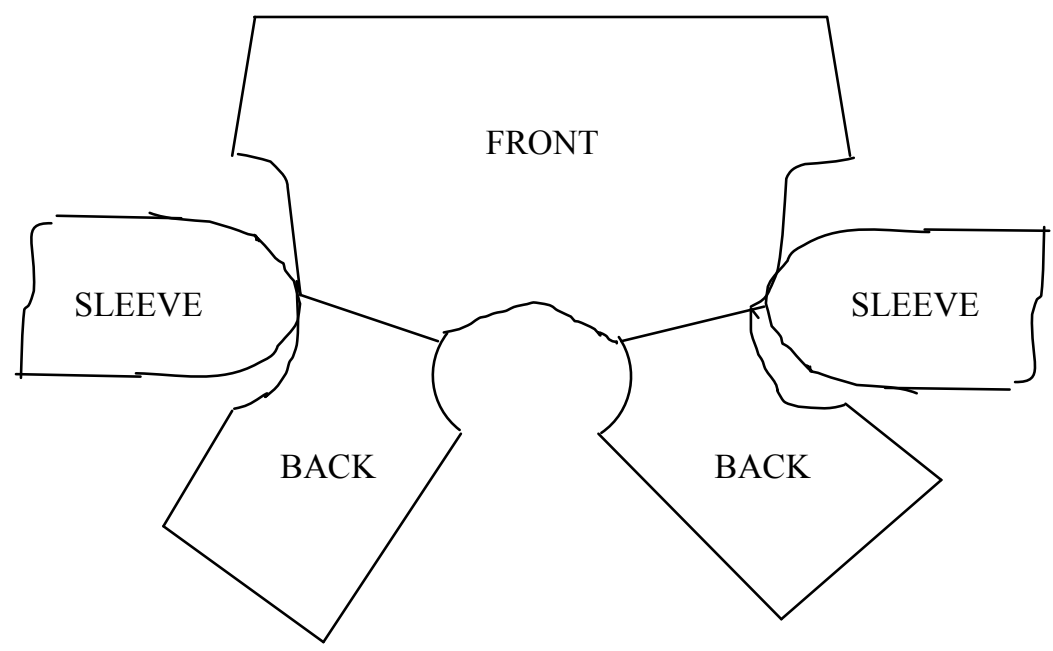

Fig. 6: (3 year olds) $1 / 4$ pattern 


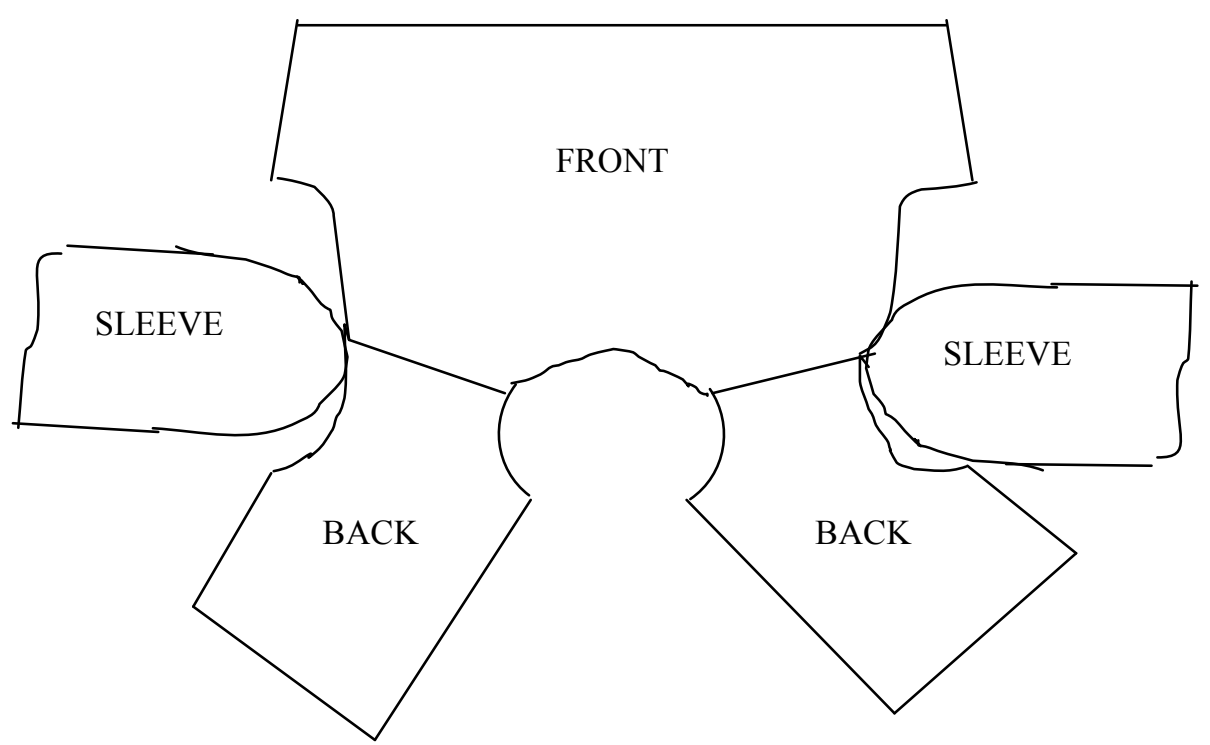

Fig. 7: ( 4 year olds) $1 / 4$ pattern

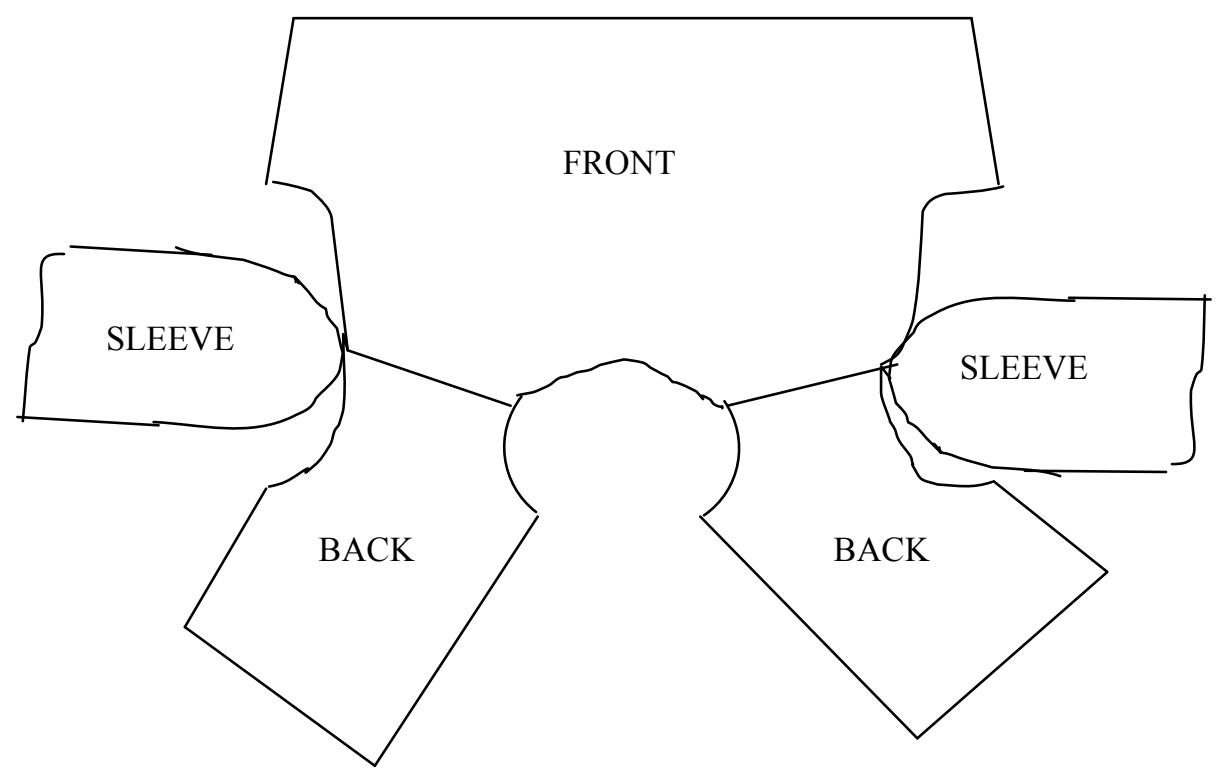

Fig. 8: (5 year olds) $1 / 4$ pattern

\section{Discussion of Findings}

Mean body parts measurement of the group used for the study showed slight differences from those subjects in Aldrich (1999). Differences existed in height, waist, chest, sleeve length, arm circumference, wrist, across back, back neck to nape to waist, under sleeve length and half length. For example average height measurements for the groups under the present study were $85.80,101,102.50$ and $107.20 \mathrm{~cm}$ respectively for ages $2,3,4$ and 5 years while the height for the subjects studied by Aldrich (1999) were 92, 98, 104 and $110 \mathrm{~cm}$. The differences in these average body measurements might be as a result of environmental factors like nutritional status. Nigeria is regarded as one of the poorest nations in the world despite 
her oil wealth. Poverty according to Igbo (2002) is one of the reasons for food insecurity. Inaccessibility and inadequacy of food are also some of the causes of food insecurity.

The study also showed variability in height, under sleeve length, sleeve length, waist, across chest, half length, arm circumference, across back and wrist from the group mean. This is also in line with Aldrich (1999), Utuk (1991) who stated that variabilities often exist in sleeve length for children of even the same age. Aldrich further stated that children born to managerial and professional parents are taller but not heavier than children of semi-skilled and unskilled parents. Waist measurements of subjects in the present study are 54, 61.70, 16.98 and $62.96 \mathrm{~cm}$ as against $51,53,54$ and $56 \mathrm{~cm}$ of the children in Aldrich study. This might be as a result of excessive consumption of carbohydrates. Carbohydrate in the form of cassava, yam, potatoes and other forms of carbohydrate are the main staples of Nigerian foods (Igbo 2002). Carbohydrate as a class of food has the ability of making an individual add extra calories if not utilized. The pre-school children studied were thus heavier but not taller. The present study indicated that some of ease at waist line existed for three groups of children which seem to agree with Aldrich (1999) who stated that very little waist shaping existed for pre-school children's garment. She also indicated that the little shaping gave the children a hollow back and protruding stomach which decrease as the children grow older and loosing baby fat. The scores for items six to ten indicated that the hollow effect reduced for the five year olds.

\section{Conclusion}

Designing for children can be very challenging because children grow continuously. To meet the challenges of mass producing dress items for pre-schools children average body measurements were taken and standardized and used for drafting patterns which are not easily available in Nigeria. Children measured for this study showed variability in the measurement of the different body parts. To correct the variability, mean of each body part was determined and used for the drafting. Patterns drafted were cut out in soft cotton fabric stitched together and modelled by some of the subjects in the study. Judges scored the fit of the garment produced based on some evaluative criteria. Comments by the judges were utilised to correct some faulty areas in the pattern before obtaining the standard blocks.

\section{Recommendations}

Based on the findings of the study the following recommendations were made

1. Mean body measurements obtained could be made available to clothing and textiles students for use in pattern drafting.

2. The block patterns obtained could be made available to textiles and clothing students for pattern drafting.

3. The block patterns could be utilised for pattern alterations.

4. Professional tailors and makers of uniforms for post primary could utilised the standard blocks for mass-producing uniforms.

5. Pattern drafting experts could use the average body measurements to draft commercial patterns.

\section{References}

Aldrich W. (1999) Metric Pattern Cutting for Children's Wear: From 2 - 14 years. Oxford. UK: Blackwell Science Ltd.

Ayodele C.A. (1995) Globalisation and Development: Ayodele Cries Out: Newswatch Vol. 1. No. 549, Nov. 11. 
Bray N. (1999) More Dress Pattern Designing: With Fashion Supplement and Illustrations. Oxford. UK: Blackwell Science Ltd.

Clayton N (1994) Young Living: New York: Glencoe McGraw - Hill Book Cor Inc.

Cooklin G. (1994) Pattern Cutting for Women's Outer wear: Oxford: Blackwell Science Publication Ltd.

Federal Republic of Nigeria (1998) National Policy on Education: Pre-primary Education: Lagos Nigeria: Nigerian Educational Research Development Council (NERDC)

Hollen N.R and Kundel C.J (1993) Pattern Making by the Flat pattern method: New York: Macmillan Publishing Company.

Hurlock E.B (1978) Child Development. New York: McGraw-Hill Book Co. Inc.

Igbo C.A (2002) Household Food Security: the Role of the Home Economist in Advocacy for Families in Nigeria. Journal of Home Economics Research Association of Nigeria. Vol. IV.

Igbo C.A and Iloeje C.I (2003) The Basics of Dress Pattern Drafting: Enugu Nigeria: Inselberg (Nigeria) Ltd.

Iloeje C.I. (1995) Establishment of Average Body Measurement and the Development of Block Patterns for Female Adolescent: Unpublished M.Ed Thesis University of Nigeria Nsukka.

Sasse C.R (1997) Families Today. New York Glencoe McGraw-Hill.

Tuit A (1983) Introducing Pattern Cutting. London: Heinemann Educational Books.

United Nations Children Education Fund (UNICEF) (1989): The United Nations Convention and OAU Charter on Rights of the child: Lagos: Nigeria Country office.

Utuk L.O. (1991) Development and Evaluation of three techniques for teaching basic pattern drafting in senior secondary schools in Akwa Ibom: Unpublished M.Ed. Thesis University of Nigeria, Nsukka. 